\title{
TRADUÇÃO FORENSE: O MAIS DIFÍCIL DOS DESAFIOS LINGUÍSTICOS?
}

\author{
Luciane Fröhlich
}

\section{Introdução}

De fato, as traduções forenses têm assumido papel fundamental dentro das esferas comunicativas globais, uma vez que há crescente mobilidade de pessoas, bens e serviços, que geram documentação jurídica internacional, entre sistemas linguísticos e jurídicos diferentes. Essa configuração multifacetada, por consequência, torna-se um grande desafio para os tradutores iniciantes. Não obstante, Susan Sarcevic (2012), reconhecendo que a tradução forense pertence à área dos Estudos de Tradução, e a caracterizando como uma tradução especializada (como na medicina, economia, direito, entre outras), complementa, afirmando que, devido à sua natureza complexa, a tradução forense é conhecida como the most complex and demanding of all areas of specialized translation $^{1}$.

Assim, as sentenças envolvidas nesse processo devem denotar alto grau de clareza e precisão (Sarcevic, 2010), preocupação essa muitas vezes esquecida pelos operadores do Direito. Polissemia, latinização, exageros linguísticos, por exemplo, são alguns dos obstáculos linguísticos, ligados à tentativa de se escrever "bem", que indicam influência retórica tradicional do Direito e que tornam a linguagem forense desafiadora, também sob o olhar da tradutologia. Desta forma, para não ficar exposto ao erro e entender melhor a linguagem jurídica, o tradutor precisa interpretar essa linguagem, como a hermenêutica jurídica por essência o faz, levando sempre em consideração o sentido e o alcance dos termos e expressões forenses, inclusive fora de seu ambiente elementar de uso, ou seja, fora dos Tribunais e/ou espaços jurídicos pátrios.

Também Deborah Cao (2007) descreve a tradução forense como pertencente a

\footnotetext{
*O presente artigo resulta das reflexões oriundas de sua Tese de Doutorado recentemente defendida no PGET / UFSC.

1 Citando as palavras de Cao (2007), ou seja, a mais complexa e exigente de todas as áreas de tradução especializada.
} 
uma categoria complexa, com leis próprias e como "o mais difícil dos desafios linguísticos", combinando a inventividade da tradução literária, com a precisão terminológica das traduções técnicas ${ }^{2}$. Porém, o que haveria de tão especial na tradução forense? Sarcevic, por exemplo, considera que a tradução forense seja possível, mas não perfeita. Ela chega a esta afirmação observando reflexões como as de J. B. White, que definia tradução forense como sendo "a arte de desafiar o possível e de enfrentar as descontinuidades intransponíveis entre textos, línguas e pessoas" ${ }^{3}$ (White, apud Sarcevic, 2012) e depois passou a qualificá-la como sendo "um processo imperfeito

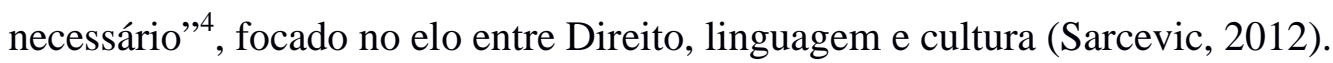

De fato, há alguns anos, a demanda por tradução de textos jurídicos tem crescido significativamente por conta do aumento do trânsito internacional de pessoas, bens e serviços. Desta forma, torna-se visível a necessidade cada vez maior de tradutores e intérpretes forenses à disposição não só da justiça direta, como também de bancos, escritórios de advocacia, empresas bi- e multinacionais, órgãos públicos (como no Ministério do Trabalho), etc.

\section{Particularidades da linguagem jurídica}

Few professions are as concerned with language as is the law.

(Tiersma, 1993)

A epígrafe acima justifica a atenção ao estudo da linguagem como sendo a matéria-prima do Direito, uma vez que, conforme Tiersma (1993), "poucas profissões

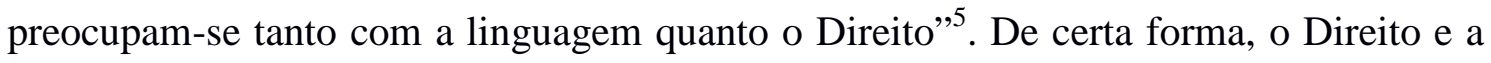
linguagem se confundem, uma vez que é por meio da linguagem jurídica, principalmente a escrita, que a doutrina, a jurisprudência e a legislação, não somente são compartilhadas, como tornam-se legítimas (Nunes, 2006).

Desta forma, faz-se necessário entender a tradução forense como um fenômeno linguístico e tradutológico. Com efeito, para melhor compreender esses fenômenos, são abordadas aqui singularidades da linguagem jurídica, entendida como uma coleção complexa de hábitos linguísticos, que se desenvolveram ao longo de vários séculos, e

2 Cairns and Mckeon 1995, Gémar 1995, Pelage 2000, todos citados por Cao, a partir de Harvey 2002.

3 Tradução minha.

4 Tradução minha.

5 Tradução minha. 
que operadores do Direito usam de forma estratégica para atingir seus objetivos ${ }^{6}$.

\title{
Juridiquês
}

O termo juridiquês, que remete aos hábitos linguísticos jurídicos, é definido neste artigo como sendo o uso da linguagem jurídica de forma extrema e complexa, que se propõe, mesmo que inconscientemente, persuadir e desorientar o texto, com o uso de recursos linguísticos altamente terminológicos (como o uso de jargão profissional), muitas vezes arcaicos (como o uso extremo de latinismos), e de construções impessoais (como o uso de passivas), que despersonalizam o autor da fala, mas que, no entanto, são frequentemente necessários para validar o gênero do documento (como leis e códigos).

\begin{abstract}
Afigura-se até mesmo ignominioso o emprego da liturgia instrumental, especialmente por ocasião de solenidades presenciais, hipótese em que a incompreensão reina. A oitiva dos litigantes e das vestigiais por eles arroladas acarreta intransponível óbice à efetiva saga da obtenção da verdade real. Ad argumentandum tantum, os pleitos inaugurados pela Justiça Pública, preceituando a estocástica que as imputações e defesas se escudem de forma ininteligível, gestando obstáculo à hermenêutica. Portanto, o hercúleo despendimento de esforços para o desaforamento do "juridiquês" deve contemplar igualmente a magistratura, o ínclito Parquet, os doutos patronos das partes, os corpos discentes e docentes do magistério das ciências jurídicas ${ }^{7}$.
\end{abstract}

Considerando o texto em destaque, bem como os apontamentos ao longo deste artigo, é possível dizer que um dos pontos que tornam a linguagem jurídica mais complexa e difícil de se entender, e, por consequência, de se traduzir, é sua constituição multifacetada. A presença de sentenças extensas e complexas, prolixidade e redundâncias, jargão jurídico, sentenças com estruturas incomuns e com construção impessoal, tornam a linguagem jurídica uma grande armadilha para o tradutor.

Essas particularidades sintático-semânticas, de estrutura e conteúdo, muitas vezes estão diretamente associadas ao sucesso ou fracasso de vários processos jurídicos, uma vez que a linguagem é comumente usada como ferramenta de persuasão e hegemonia linguística. Na sequência, há outro exemplo ${ }^{8}$ de juridiquês que demonstra,

6 Baseado em Tiersma, 1999.

7 Extrato do texto "Entendeu?", do desembargador Rodrigo Collaço, ex-presidente da AMB, em prol da simplificação da linguagem jurídica (AMB, 2007).

8 Jornal do Senado (Fonte: Revista Língua Portuguesa). Acessível em: http://www12.senado.gov.br. 
de forma compilada, uma amostra da linguagem jurídica em ação.

Com espia no referido precedente, plenamente afincado, de modo consuetudinário, por entendimento tumário iterativo e remanso, e com ampos supedâneo na Carta Política, que não preceitua garantia ao cotencioso nem absoluta nem ilimitada, padecendo ao revés dos temperamentos constritores limados pela dicção do legislador infraconstitucional, resulta de meridiana clareza, tornando despicienda maior peroração, que o apelo a este Pretório se compadece do imperioso prequestionamento da matéria abojada na insurgência, tal entendido como expressamente abordada no Acórdão guerreado, sem o que estéril se mostrará a irresignação, inviabilizada ab ovo por carecer de pressuposto essencial ao desabrochar da operação cognitiva.

Esse exemplo é um extrato, embora exagerado, que pode ser qualificado como uma amostra contundente de juridiquês. Ele representa, em síntese, o quão distante do português a linguagem jurídica se encontra. Exageros terminológicos (como o uso dos termos "carta política", "pretório", "acórdão guerreado"), aliados a floreios (como o uso da locução latina $a b$ ovo) e itens lexicais exacerbados da língua culta (como "supedâneo", “despicienda" ou “abojada”), são encontrados em muitas peças jurídicas brasileira, que antes de sua tradução para uma possível língua estrangeira, carece de uma tradução intralingual ${ }^{9}$, ou seja, uma tradução para o próprio vernáculo.

Assim o fez o advogado Sabatini Giampietro Netto ${ }^{10}$, por meio da sugestão de "tradução" (do juridiquês para o português) do referido extrato:

Um recurso, para ser recebido pelos tribunais superiores, deve abordar matéria explicitamente tocada pelo tribunal inferior ao julgar a causa. Isso não ocorrendo, será pura e simplesmente rejeitado, sem exame do mérito da questão.

Esse extrato apresenta apenas algumas pistas da dimensão do problema que a linguagem jurídica pode trazer para os tradutores forenses. A união de componentes complexos, como o uso de itens lexicais incomuns, faz com que a linguagem jurídica seja enquadrada como uma linguagem super especializada, denominada de "juridiquês".

Último acesso em dezembro de 2013.

9 Que pode nos remeter aos ensinamentos de Jakobson, que considera a tradução intralingual, ou reformulação (rewording), uma interpretação dos signos verbais, por meio de outros signos da mesma língua (Jakobson, 1971).

10 Fonte: Revista Língua Portuguesa (tradução feita pelo advogado Sabatini Giampietro Netto), por intermédio do Jornal do Senado. Acessível em: http://www12.senado.gov.br. Último acesso em dezembro de 2013. 
O juridiquês ${ }^{11}$ é definido primariamente como o uso excessivo do jargão jurídico e de termos técnicos do Direito. Não obstante, seu sentido vai além.

O juridiquês é defendido pelos juristas mais clássicos, com o argumento de que desta forma não haveria lacunas de interpretação no texto, e odiado pelos vanguardistas, que prezam por uma linguagem jurídica mais limpa, clara e eficiente. A procura por uma linguagem rebuscada e perfeita, associada à precisão de sentido, pode levar o jurista à formação de sentenças truncadas, evasivas, o que leva à falsa interpretação. Nesse caso, forma-se um abismo linguístico, em que de um lado se encontra o profissional forense $^{12}$ e do outro a população em geral. A linguagem permanece no centro, obscura e imperfeita aos olhos da concisão.

De um modo geral, frases em juridiquês podem ser de difícil compreensão até mesmo para juristas. Valdeciliana da Silva Ramos Andrade ${ }^{13}$, por exemplo, em seu artigo "O juridiquês e a linguagem jurídica: o certo e o errado no discurso" (Andrade, 2009), discorre sobre o assunto de maneira aberta. Segunda ela, "há que se acrescentar que juridiquês não é só o uso de arcaísmos, palavras rebuscadas, neologismos, latinismos e o uso inadequado da língua portuguesa, mas também contribui para a existência do juridiquês a produção textual truncada, extensa”.

Desta forma, o uso do juridiquês põe em xeque o ofício do jurista, na medida em que este falha na exposição clara de seus textos, contrariando sua essência romana de interpretar para os cidadãos comuns, as normas escritas a eles até então não reveladas. De fato, pode-se julgar que tais exemplos são neologismos que afrontam a língua portuguesa, pois saem da esfera de meros sinônimos, utilizados para formar um texto coeso e coerente, e entram na esfera prolixa do discurso escrito. Com efeito, Andrade (ibidem) menciona que um texto jurídico bem escrito deve conter apenas o essencial, "falar o que deve ser dito, argumentar com coerência e precisão, averiguar o veículo adequado da comunicação e vislumbrar o destinatário, sabendo que, muitas vezes, este nem sempre coincide com interpretante real. O desafio está posto."

Infelizmente a realidade textual corrente é outra. Uma amostra real de texto, com traços de juridiquês, pode ser observada nas figuras abaixo, que apresentam um extrato

11 Legalese, em inglês; Juristendeutsch, em alemão; ou mesmo Jerga legal, em espanhol.

12 Também chamado de operador do Direito ou jurista, é considerado aqui qualquer profissional bacharelado e atuante na área do Direito.

13 Professora de Linguagem Jurídica da Faculdade de Direito de Vitória/FDV. 
de uma sentença julgada em 2003.

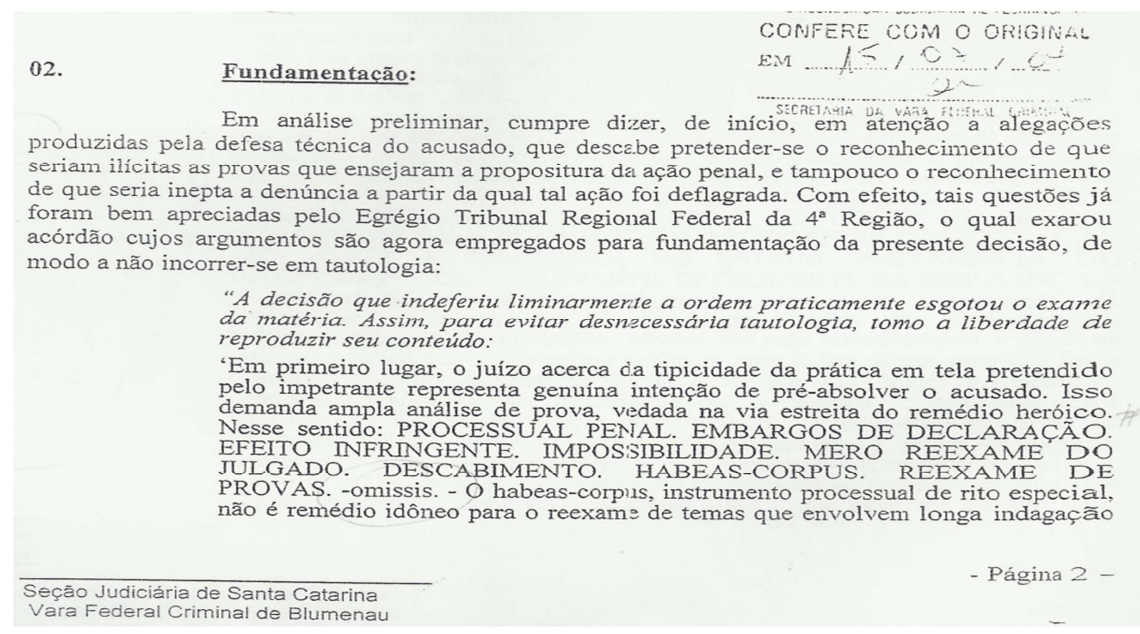

Figura 1: Amostra de juridiquês (anverso).

\section{PODER JUDICIÁRIO JUSTIÇA FEDERAL}

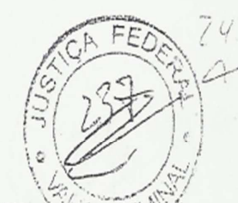

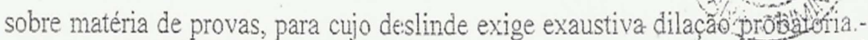
omissis. (STJ, EDEDHC n ${ }^{\circ}$ 10946/Ri, Rel. Min. Vicente Leal, Sexta Turma, DJ de 05.02 .2001 , p. 127) PROCESSUAL PENAL. HABEAS CORPUS. CRIMESOCIETARIO. DENÚNCIA. DESCRICÃO PORMENORIZADA DA CONDUTA DOS AGENTES. DESNECESSIDADE. $1=$ omissis. II - A falta de justa causa, por outro lado, só pode ser admitida se detectável de plano, sem recurso ao vedado cotejo analítico da prova. Writ indeferido. (STJ, HC $n^{\circ}$ 12880/GO, Rel.Min. Felix Fischer, Quinta Turma, DJ de 05.02.2001, p. 118) Resta, então, analisar se, in these, a ação descrita na denúncia enquadra-se na previsão do parágrafo único do art. 22 da Lei n $n^{\circ} 7.492 / 86$, assim redigido: Art. 22. Efetuar operação de câmbio não autorizada, com o fim de promover evasão de divisas do País: Pena - reclusão, de 2 (dois) a 6 (seis) anos, e multa.

Figura 2: Amostra de juridiquês (verso).

São muitos os pontos que chamam a atenção no texto em questão (figuras 1 e 2): uso de metáforas ("vedada na via estreita do remédio heroico"); latinismos (in these, omissis, habeas corpus); terminologia específica ("sobre matéria de provas", "para cujo", "deslinde exige exaustiva dilação probatória", "vedado cotejo analítico da prova"); termos em inglês (Writ); demarcação de ênfase com uso de caixa alta (PROCESSUAL PENAL. HABEAS CORPUS. CRIMESOCIETÁRIO. DENÚNCIA. DESCRIÇÃO PORMENORIZADA DA CONDUTA DOS AGENTES. 
DESNECESSIDADE), etc. Essa linguagem tão peculiar ao Direito torna-se um grande percalço ao tradutor forense, principalmente ao iniciante.

De fato, existe um postulado aceito no mundo jurídico de que "quanto mais rebuscado o texto, mais aceito pela sociedade forense ele é”. Todavia, há um paradoxo nesse axioma, visto que para uma linguagem ser precisa, requisito da linguagem forense, ela precisa ser clara, sucinta e exata. Andrade (ibidem), em seu artigo sobre juridiquês, observa que "[...] em geral, o uso descomedido do latim, por exemplo, visa denotar uma falsa cultura, que, em geral, funciona como elemento de distanciamento entre o operador do Direito e o homem comum o qual, muitas vezes, é uma pessoa culta, com curso superior, entre outros predicativos." Num primeiro momento, uma linguagem rebuscada, latinizada, arcaica, pode denotar cultura e conhecimento, não obstante, o que se percebe nos bastidores dos textos forenses é um uso desfreado de expressões "desconhecidas" ao povo leigo, que servem para demarcar uma hegemonia sobre o assunto, acarretando em desnível não só linguístico, como cultural.

\section{Prolixidade como um hábito linguístico da linguagem jurídica brasileira}

Hábito linguístico (jurídico) é caracterizado como sendo o uso ordinário da linguagem culta, terminológica, de sentenças extensas e complexas, redundâncias, latinismos, construções impessoais, além de outros mecanismos de persuasão linguística. De fato, os hábitos linguísticos colaboram na caracterização do juridiquês, na medida em que tornam a linguagem jurídica brasileira altamente complexa e terminológica.

Com efeito, são trabalhadas nessa seção algumas particularidades associadas à prolixidade, que colaboram na caracterização da linguagem jurídica brasileira como desafiadora. Elas frequentemente estão presentes em documentos jurídicos, tornando-os longos, não raras as vezes, redundantes e incoerentes. Com efeito, o termo "prolixo" é definido, pelo Novo Dicionário Aurélio da Língua Portuguesa, como sendo:

[Do latim prolixu.] Adj. 1. Muito longo ou difuso. 2. superabundante, excessivo, demasiado. 3 [...] dilatado [...]. 4. P. ext. fastidioso, enfadonho [...]. [Antônimo: conciso]

(Holanda, 1986, p. 1400). 
Inicialmente considerada um fenômeno sintático, a prolixidade lida com a organização dos constituintes das frases. No entanto, suas características não necessariamente fazem referência a uma relação lógica entre as múltiplas combinações possíveis para transmitir um significado completo e compreensível, elas tocam também nas esferas da semântica, que trata da relação entre os significantes do texto. A prolixidade, portanto, está ligada à complexidade técnica da língua, sendo um obstáculo sintático-semântico real aos destinatários, e, por consequência, aos tradutores.

Não obstante, outra explicação, bastante comum também na língua inglesa, poderia estar associada à necessidade de os advogados serem tão precisos e completos quanto possível, o que acaba promovendo o uso de vários itens lexicais semelhantes, bem como o reuso de frases inteiras utilizadas com sucesso anteriormente. Em alguns casos, ela pode estar associada também ao uso do computador, que facilitou ainda mais o ato "copiar e colar" de documentos passados. Além disso, o uso de citações de outras ações é um recurso adotado por vários advogados para justificarem seu pleito, em virtude do gênero ${ }^{14}$ ser o mesmo, acarretando em petições longas, muitas vezes sem nexo, e, por consequência, prolixas.

Uma amostra dessa característica textual pode ser observada na figura 3. Esse texto é um extrato linguisticamente complexo de uma ação cautelar de arrolamento de bens, de 2010, direcionada à $1^{\text {a }}$ Vara da Família da Comarca da Capital de Santa Catarina, com a citação de Rubens Requião, remetendo à Teoria da Personalidade Jurídica (RT 410/12).

14 O gênero força o uso de uma estrutura padrão, como é o caso de uma petição, gerando documentos similares. Em busca rápida pela internet, encontrou-se inúmeros modelos de petições, com e sem citações teóricas, o que sugere ser uma prática frequente recorrer a modelos pré-prontos, que acabam aumentando a taxa de insucesso linguístico do texto jurídico final, uma vez que muitos não seguem a coesão e a coerência necessárias. 
4.7. A propósito do tema, ensina RUBENS REQUIÃO (Teoria da Personalidade Jurídica, in RT 410/12) que:

"... a doutrina da desconsideracão nega precisamente o absolutismo do direito da personalidade jurídica. Desestima a doutrina esse absolutismo, perscruta através do véu que a encobre, penetra no seu âmago, para indagar de certos atos dos sócios ou do destino de certos bens. Apresenta-se, por conseguinte, a concessão da personalidade jurídica com um significado ou um efeito relativo e não absoluto, permitindo a legitima penetração inquiridora no seu âmago."

Figura 3: Exemplo de prolixidade.

Este texto foi reproduzido pelos advogados da dita ação cautelar para, com o uso da doutrina da desconsideração, acusar o requerido, enquadrando-o dentro dessa doutrina "que serve para responsabilizar os membros de uma empresa pelos danos que causem a terceiros e ao Estado sob o manto da personalidade jurídica". Ele é considerado linguisticamente complexo pelo ponto de vista da tradução forense por abarcar terminologia difusa, aliada a um conjunto de termos que, a princípio, não pertencem ao ambiente jurídico, causando estranhamento do gênero "ação cautelar".

A propósito, em uma ação cautelar "se pleiteia medida que assegure a eficácia de um processo distinto" (Acquaviva, 2006, p. 26). Com efeito, parece prudente que uma ação cautelar se faça de maneira clara, o que não se constata na referida amostra, principalmente em se tratando da necessidade de uma possível tradução, na qual a polissemia da linguagem jurídica brasileira normalmente não se enquadra. Um exemplo dessa prolixidade é o uso das expressões metafóricas "cobrir com véu” e "penetrar/penetração no âmago", presentes no período "Desestima a doutrina esse absolutismo, perscruta através do véu que a encobre, penetra no seu âmago, para indagar de certos atos dos sócios ou do destino de certos bens" e no final em "permitindo a legítima penetração inquiridora no seu âmago". O termo "penetração", por exemplo, é uma amostra de termo causador de estranhamento no texto, uma vez que remete a um sentido sexual do referido item lexical. De fato, em situações como essa, o tradutor iniciante deve tomar uma série de decisões-chave.

Em casos como esse, uma simplificação da fala jurídica costuma ser eficaz como estratégia de tradução, no entanto, remete a questões polêmicas da linguagem jurídica, que fazem parte de muitas mesas de discussões, cada vez mais frequentes, e com histórico de longa data. O filósofo, e também jurista, Sir Francis Bacon, por exemplo, 
propôs, no ano de 1593, uma grande reforma no legislativo britânico, pois já havia se convencido que a linguagem jurídica não atingia a todos os interessados pelo Direito. William Hepworth Dixon publicou, no ano de 1861, alguns textos com falas inéditas comentadas de Francis Bacon. Dentre eles, recorta-se o seguinte extrato de texto, datado de 26 de fevereiro de 1593:

[...] The House starts up. The tide might have come in from the Thames. Reform the code! Bacon tells a House full of Queen's counsel, Queens's serjeants, and utter barristers, that laws are made to guard the rights of the people, not to feed the lawyers. The laws should be read by all, known to all. Put them into shape, inform them with philosophy, reduce them in bulk, give them into every man's hand (Dixon, 1861, p. 34).

Destaca-se desta citação o trecho laws are made to guard the rights of the people, not to feed the lawyers. The laws should be read by all, known to all. Put them into shape, inform them with philosophy, reduce them in bulk, give them into every man's hand, em que Bacon fala publicamente sobre a popularização do Direito, defendendo que as leis devem ser lidas (e entendidas) por todos os cidadãos, servindo, deste modo, não apenas para "alimentar os advogados". E para popularizar a linguagem, é necessário simplificá-la.

De fato, traduzir textos prolixos exige muita reflexão e desenvoltura. E o texto usado como exemplo (extrato de uma ação cautelar) é uma pequena amostra do que um tradutor pode encontrar ao traduzir documentos jurídicos. Com base nisso, a sugestão é que o tradutor faça uma análise rigorosa do documento, em busca do sentido real do texto, não se limitando ao sentido das palavras, mas sim das frases e das figuras de linguagem, bem como assuma o desafio linguístico proposto pelo texto jurídico, ponderando todas as faces do problema, "transformando" o texto original pouco coerente/coeso em um texto traduzido limpo e o mais informativo possível.

É igualmente importante que o tradutor iniciante tenha acesso a um bom glossário de equivalentes jurídicos, a um corpus grande de documentos relevantes similares (como os disponibilizados pelo Parlamento Europeu), bem como habilidade em usar software de tradução (como Wordfast ${ }^{15}, \operatorname{Trados}^{16}$ ou DejaVu ${ }^{17}$ ). Além disso, é 
aconselhável que o tradutor iniciante procure um jurista para sanar as últimas dúvidas. Somente depois desse processo de reflexão, análise e reconhecimento da linguagem envolvida é que a tradução deveria ser executada.

Tais desafios da hermenêutica jurídica exigem, no entanto, atenção redobrada por parte do tradutor, bem como conhecimento profundo e especializado nas línguas envolvidas. Soma-se aqui também a responsabilidade civil e criminal às quais o tradutor forense é exposto, elevando exponencialmente sua responsabilidade tradutológica.

\section{Considerações Finais}

Há necessidade cada vez mais crescente da tradução de textos jurídicos, apesar da paradoxal imperfeição associada à tradução forense, que de um lado almeja equivalência jurídica, através de traduções precisas e juridicamente confiáveis, e de outro reconhece que as traduções seriam apenas a melhor aproximação do original (Sarcevic, 2010).

Com efeito, trabalhar essa imperfeição com perícia é papel fundamental do tradutor, que deve orientar-se à execução concisa e coerente da tradução, com foco na obtenção do mesmo efeito jurídico do documento jurídico da língua de partida, também na língua de chegada.

Como contributo a essa questão, o presente artigo procurou evidenciar, ao tradutor iniciante, pontos de dificuldade na tradução de textos prolixos, do contexto forense brasileiro, bem como sinalizar sugestões de como lidar com os obstáculos associados à tradução dessa linguagem, que é considerada por muitos como sendo o mais difícil dos desafios linguísticos (Cao 2007). Considerando o conjunto dessas reflexões, conclui-se que, de fato, a linguagem jurídica brasileira é complexa e merece muita atenção, tanto por parte do tradutor, que traduz os documentos jurídicos, quanto por parte dos operadores do Direito, que os elaboram.

Dentro desse contexto, parece prudente pensar em uma simplificação da linguagem jurídica, que se oriente à diminuição de barreiras linguísticas dentro das esferas comunicativas (entre os agentes de diálogo: operadores do Direito e público

16 http://www.sdl.com/products/sdl-trados-studio/

17 http://www.dejavusoftware.com/ 
leigo) o que contribuiria para um melhor desempenho dos tradutores. Não obstante, a competência do tradutor iniciante, para lidar com situações-problema, como as apontadas ao longo deste artigo, é tão importante quanto a simplificação da linguagem jurídica a ser trabalhada por ele. Desta forma, o que se constata é que só haverá legitimidade tradutória se houver compreensão real do que se traduz, o que, por sua vez, só existirá se a linguagem jurídica deixar de ser provida de hábitos jurídicos complexos e o tradutor tiver formação especializada em tradução forense.

\section{Referências bibliográficas}

ACQUAVIVA, Marcus. Dicionário jurídico brasileiro Acquaviva. SP: Editora Jurídica Brasileira, 2006.

AMB, Associação dos Magistrados Brasileiros. O judiciário ao alcance de todos - Noções básicas de juridiquês. Brasília: AMB, 2007.

ANDRADE, Valdeciliana. O juridiquês e a linguagem jurídica: o certo e o errado no discurso. 2009. Disponível em <http://www.amatra17.org.br>.

CAO, Deborah. Translating Law. Clevedon: Multilingual Matters, 2007.

DIXON, William (Ed.). Personal history of Lord Bacon: From unpublished papers. Londres, Inglaterra: John Murray, 1861.

FROHLICH, Luciane. Tradução Forense: um estudo de cartas rogatórias e suas implicações. Tese (doutorado) - Universidade Federal de Santa Catarina, 2014 (no prelo).

HOLANDA, Aurélio. Novo Dicionário Aurélio. Rio de Janeiro: Nova Fronteira, 1986.

JACOBSON, Roman. Linguística e comunicação. In: Aspectos linguísticos da tradução. São Paulo: Cultrix, 1971.

NUNES, Rizzatto (ed.). Manual de introdução ao estudo do direito. SP: Saraiva, 2006.

TIERSMA, Peter. Legal Language. Chicago Press, 1999.

TORRES, Simone; ALMEIDA, Maurício. Documentação jurídica: reflexões sobre a função social do documento legislativo. Proceedings do II Congresso Brasileiro em Representação e Organização do Conhecimento.

SARCEVIC, Susan. Legal Translation in Multilingual Settings. Granada: Comares, 2010. FGV, Rio de Janeiro, 2013. . Challenges to the Legal Translator. Oxford, 2012.

WHITE, James Boyd. Justice as Translation. Chicago Press, 1990. 